\title{
Does the online collection of ego-centered network data reduce data quality? : an experimental comparison
}

\section{Citation for published version (APA):}

Matzat, U., \& Snijders, C. C. P. (2010). Does the online collection of ego-centered network data reduce data quality? : an experimental comparison. Social Networks, 32(2), 105-111.

https://doi.org/10.1016/j.socnet.2009.08.002

DOI:

10.1016/j.socnet.2009.08.002

Document status and date:

Published: 01/01/2010

\section{Document Version:}

Publisher's PDF, also known as Version of Record (includes final page, issue and volume numbers)

\section{Please check the document version of this publication:}

- A submitted manuscript is the version of the article upon submission and before peer-review. There can be important differences between the submitted version and the official published version of record. People interested in the research are advised to contact the author for the final version of the publication, or visit the $\mathrm{DOI}$ to the publisher's website.

- The final author version and the galley proof are versions of the publication after peer review.

- The final published version features the final layout of the paper including the volume, issue and page numbers.

Link to publication

\section{General rights}

Copyright and moral rights for the publications made accessible in the public portal are retained by the authors and/or other copyright owners and it is a condition of accessing publications that users recognise and abide by the legal requirements associated with these rights.

- Users may download and print one copy of any publication from the public portal for the purpose of private study or research.

- You may not further distribute the material or use it for any profit-making activity or commercial gain

- You may freely distribute the URL identifying the publication in the public portal.

If the publication is distributed under the terms of Article 25fa of the Dutch Copyright Act, indicated by the "Taverne" license above, please follow below link for the End User Agreement:

www.tue.nl/taverne

Take down policy

If you believe that this document breaches copyright please contact us at:

openaccess@tue.nl

providing details and we will investigate your claim. 


\title{
Does the online collection of ego-centered network data reduce data quality? An experimental comparison
}

\author{
Uwe Matzat*, Chris Snijders \\ Eindhoven University of Technology, The Netherlands
}

\section{A R T I C L E I N F O}

\section{Keywords:}

Web surveys

Data quality

Online data collection

Experiment

Social network data

\begin{abstract}
A B S T R A C T
We analyze whether differences in kind and quality of ego-centered network data are related to whether the data are collected online or offline. We report the results of two studies. In the first study respondents could choose between filling out ego-centered data through a web questionnaire and being probed about their network in a personalized interview. The second study used a design in which respondents were allocated at random to either online or offline data collection. Our results show that the data quality suffers from the online data collection and the findings indicate that this is the consequence of the respondents answering "mechanically". We conclude that network researchers should avoid to simply copy traditional network items into a web questionnaire. More research is needed about how new design elements specific for web questionnaires can motivate respondents to fill out network questions properly.
\end{abstract}

(C) 2009 Elsevier B.V. All rights reserved.

\section{Introduction}

Traditionally, the measurement of ego-centered social networks is done with the help of an interviewer who is available for assistance and who can motivate the respondent to continue with the answering procedure. The most often used method to collect egocentered network data was proposed by Burt (1984). It has been used in some of the US General Social Surveys since 1984 (see e.g., McPherson et al., 2006) and proceeds in three steps. In the first step the respondent (ego) is confronted with a name generator: a question in which the respondent is probed to list a limited number of individuals (alteri) with whom he is in a well-defined, usually close relationship. In the second step a number of questions (name interpreters) about the characteristics of the cited alteri and about the relationship of the respondent with the alteri are asked. In the third step, data about the relationships between the different alteri within ego's social network are collected, effectively filling out the inter-alter response matrix.

The outcomes of the measurements when carried out using a paper-and-pencil-with-interviewer context are known to be sensitive to details of the measurement procedure. The measurements do not provide a perfect picture of the respondent's recent interaction (Brewer, 2000; Bernard et al., 1982; Bell et al., 2007). Respondents are also not good in recalling specific interactions

\footnotetext{
* Corresponding author at: Eindhoven University of Technology, PO Box 513, 5600 MB Eindhoven, The Netherlands. Tel.: +31 402478392.

E-mail address: u.matzat@tue.nl (U. Matzat).
}

or interactions that took place within a specific time boundary. However, respondents are reasonably good at reporting their typical, stable social relations (Freeman et al., 1987). There is some bias and error in the respondents' recall of their relations, but we have some, although limited, information about the types of biases that emerge. For example, when confronted with a name generator, it is likely that a respondent mentions his or her frequent and close contacts, contacts that are more central in the network, and multiplex relationships rather than his or her infrequent, distant, less central or one-dimensional instrumental contacts (Kogovsek and Ferligoj, 2004; Brewer, 2000; Marin, 2004). Also, there is a high test-retest stability of the names reported in the name generators (Marsden, 1990). The quality of the data obtained by the name interpreter, measured by the degree of overlap between the reports of ego and alter on alter's characteristics, tends to be high for socio-demographic characteristics of the alteri, but much lower for attitudes or opinions (Marsden, 1990). The quality of the data on the characteristics of the relationships between ego and alter, measured by the degree of concordance in the reports of alter and ego, tends to be particularly high for close ties and general types of interaction. This is known for characteristics of the relationship such as the frequency of interaction, its duration, and its intensity (Marsden, 1990). The quality of the data on characteristics of the relationships between the alteri as collected through the inter-alter response matrix tends to be somewhat lower. Adams and Moody (2007), in a study of drug users, report that about $87 \%$ of inter-alter ties that were mentioned by ego were corroborated by the alteri.

Scientific findings and empirical experience show that the adequate measurement of the respondents' network characteristics 
is time-consuming and demanding for the respondent. Therefore, until recently, almost all network studies were conducted by means of a personal interview. The interviewer motivates the respondent to complete the survey, (s)he can explain the procedure in detail, and the respondent can ask questions. Obviously, the face-to-face interaction has disadvantages as well. It is expensive and timeconsuming for the researcher, and may create interviewer effects that are hard to control for (Marsden, 2003). While a web-based survey eliminates interviewer effects (Lozar Manfreda et al., 2004) and allows for cheaper and faster data collection, it is unclear which other, perhaps disadvantageous, effects this may have. The online measurement may lead to a lower data quality with respect to missing values and selectivity. Kogovsek et al. (2002) showed that the collection of ego-centered network data is possible by means of a telephone interview. Kogovsek (2006) compared reliability and validity of ego-centered network measures collected by means of a web survey with those collected by means of a telephone interview. Reliability and validity indicators were only slightly lower in the web survey data. However, no information about dropouts or missing values was given and the study did not include the inter-alter response matrix. In fact the collection of ego-centered network data by means of a web survey is already on its way (e.g., Marin, 2004), but we have limited if any knowledge about how this affects the quality of the measured network data.

Lozar Manfreda et al. (2004) and Vehovar et al. (2008), in experimental studies, show that the measured network size in a web survey depends on the details of the used name generator. The more placeholders are presented for the recall of relevant alteri, the more alteri are recalled (and consequently the larger the size of the network). The larger the network size, the higher the dropout rate in the later parts of the network data collection. Coromina and Coenders (2006), in a comparison of different design elements of web questionnaires, conclude that ordering the name interpreters by question (instead of by alter), having items with labeled categories, and using graphical elements increase the reliability and validity of the network data. Coromina and Coenders (2006) as well as Kogovsek (2006) suggest that online collection of social network data could lead to a satisfactory reliability and validity. However, their studies do not take into account the crucial issue of missing values. Moreover, they do not assess to what extent their findings are affected by, or may even be the consequence of, undesirable answering tendencies that are specific for web questionnaires, such as a mechanically clicking until the end of the survey is reached. Survey methodologists argue that selfadministered surveys may affect the respondent's motivation to fill out questions, leading to a higher rate of missing data (Tourangeau et al., 2007). This might be true especially for the time-consuming and burdensome network measurements in web surveys (McCarty et al., 2007). Respondent's burden, in turn, is known to influence the answering behavior in web surveys (Crawford et al., 2001). Before we take the quality of ego-centered network data collection for granted, it is important to study in more detail whether this mode of data collection, when compared to a data collection by means of a face-to-face interview, does have any disadvantages. In this article we focus on data quality in the sense of the respondent's accuracy of self-reported information (Marsden, 1990; Killworth and Bernard, 1976). We concentrate on three specific indicators of accuracy, namely missing values in single network items, survey dropout during the network questions, and answering bias. The network data includes data obtained by the use of name generators, name interpreters, and the inter-alter response matrix. In the following sections we present the results of two studies that help to answer these questions. The first explorative study allowed the respondents to choose freely between the two modes of data collection. The second study uses random allocation of respondents.

\section{A non-random comparison of online and offline data collection}

In June 2004 we asked a number of researchers at Eindhoven University of Technology to participate in a short Dutch language survey concerning their collaboration with (commercial) companies outside the university. Respondents were 110 researchers from a variety of disciplines, from six different faculties: Biomedical Engineering (29), Architecture, Building and Planning (20), Electrical Engineering (15), Chemical Engineering and Chemistry (14), Applied Physics (10), and Mechanical Engineering (20). Two participants did not answer the question about their faculty. Almost all of the participants were male (93\%). Different kinds of researchers participated: $13.9 \%$ full professors, $14.8 \%$ associate professors, $31.5 \%$ assistant professors, $5.6 \%$ researchers or postdocs, $32.4 \%$ Ph.D. students, $1.9 \%$ had another function and two respondents did not answer this item. The questionnaire included 36 questions about the involvement in and motivation for collaboration with companies, success of the last collaboration, and several other aspects related to dealing with business firms. At the end of the questionnaire eight network questions (4 name generators, 3 name interpreters, 1 inter-alter response matrix) were asked. Students contacted the respondents by phone and asked them for a face-to-face interview that would take about $30 \mathrm{~min}$ in order to complete. If the respondents indicated to have no time within the next 2 weeks then they were offered the opportunity to fill out the survey online. The 13 students were briefly trained for the interview and each was instructed to contact 13 respondents, randomly selected from a list of researchers at the faculties. Out of the resulting 169 respondents that were reached, 110 agreed to answer the questions, a $65 \%$ response rate. From these 110,43 of the respondents were interviewed face-to-face, 67 respondents decided to fill out the online questionnaire. During the interview the respondent was handed the questionnaire and the student read the questions aloud and wrote down the answers. The online questionnaire was designed in such a way that it was identical to the offline version, with the exception of the online version using automatic skipping of questions whenever appropriate. Filling out a question was not mandatory for the respondent. In the network part, all respondents were asked to name personal contacts that could be of value when they wanted to get in contact with a commercial company to discuss potential cooperation. We used four name generators (see Appendix A) to ask for the following types of contacts: (a) contacts within their own faculty, (b) contacts within the university, but outside their own faculty, (c) contacts within companies, and (d) private contacts. For every type of contact up to three pseudonyms could be mentioned. Furthermore, we prompted for up to three additional non-specific relevant persons who the respondent considered important for getting a business cooperation going so that the total network could consist of up to 15 persons. Burt (1997), in a study of managers, suggests that similar name generators of this type are usable for measuring the most valued advice contacts. In our study, the name generators were followed by three name interpreters: 1 . Please indicate for every individual mentioned below how easy it is for you to exchange information with him or her. 2. Please indicate for every individual mentioned below how often did you contact him of her, either face-to-face or via telephone, email etc.? 3. Please indicate for every individual mentioned below to what extent has he or she been helpful for you in the building up of a collaboration with a commercial company? Finally, the respondent was asked to assess the relationship strength (strong, weak, non-existent, don't know) for every pair of alteri in the inter-alter response matrix (see Appendix B).

The two groups of respondents (online vs. face-to-face) do not differ significantly with regard to their self-assessed prominence, their number of research projects during the last 2 years, their func- 
Table 1

Differences in network size for respondents with size $>0^{a}$.

\begin{tabular}{|c|c|c|c|}
\hline & Online & Face-to-face & $p$-Value of $t$-test \\
\hline Within faculty network (0-3) & 2.4 & 2.2 & 0.26 \\
\hline Outside faculty network ( $0-3)$ & 0.9 & 1.0 & 0.62 \\
\hline Business network $(0-3)$ & 1.5 & 1.8 & 0.29 \\
\hline Personal network (0-3) & 1.5 & 2.0 & 0.05 \\
\hline Residual network & 0.3 & 0.2 & 0.20 \\
\hline Total network size $^{\mathrm{b}}(1-15)$ & 6.2 & 6.8 & 0.39 \\
\hline
\end{tabular}

a Note: Given our sample size, we can expect to find differences if they are of size 0.7 or bigger for the four subnetworks, and of size 1.8 or bigger for the complete network ( power $=0.8$, alpha $=0.10$ ).

b The sizes of the subnetworks do not add up to the total network size because of rounding imprecisions.

tion, their faculty, and how appealing cooperation with a company is to them (Fisher's exact values: 0.18, 0.85, 0.59, 0.23, 0.94). They also do not differ significantly with respect to the number of missing values in any of the non-network variables and no respondent dropped out before the network part of the questionnaire. Dropout rates in the network part were higher in the online data collection $(18 / 67=0.27)$ than in the face-to-face interview $(3 / 43=0.07$, Fisher's exact value $=0.02$ ). In the online group the number of dropouts increased from 13 in the name generator part to 17 in the name interpreter part and 18 in the matrix. During the faceto-face interviews three respondents refused to answer the name generator questions. Among those respondents who filled out at least one alter pseudonym in the name generator questions there is no evidence for large differences in the size of the networks (see Table 1).

There are no significant differences between the groups in the mean values of the answers mentioned in the name interpreters. However, among respondents who filled out the web survey there is a significantly larger proportion of respondents with missing values for all three name interpreters: first interpreter: 6/51 vs. $0 / 40$ (Fisher's exact value $=0.03$ ), second interpreter: $8 / 50$ vs. $0 / 40$ (Fisher's exact value $=0.01$ ), third interpreter: $14 / 50$ vs. 4/40 (Fisher's exact value $=0.04$ ). Moreover, among the web survey participants there is a larger proportion of respondents who filled out the same value for all alteri in the last (third) name interpreter: $16 / 41$ vs. 3/36 (Fisher's exact value < 0.01). In the inter-alter response matrix the proportions of respondents who have chosen "don't know" answers do not differ significantly. However, among the web respondents there is a higher likelihood of having at least one missing value: $7 / 44$ vs. 0/39 (Fisher's exact value $=0.01$ ). Moreover, these respondents also have a higher number of missing values: $\bar{X}_{1}=3.7, \bar{X}_{2}=0(p=0.04)$. The network densities between both groups also differ both for binary ties ( 0.61 vs. $0.49, p=0.04)$ and for valued ties ( 1.1 vs. $0.78, p=0.01$ ). This can be explained by the following. Among the web respondents (excluding missing values and don't know answers) there is a larger proportion of participants who have chosen the same answer category for all inter-alter ties: 9/43 vs. 0/38 (Fisher's exact value <0.01). All 9 web respondents who have chosen the same value, claim that all of their inter-alter ties are 'very strong' which was the first answer category out of the four categories in the drop-down menu.

We conducted several multiple logistic regression analyses on the likelihood of dropping out, the likelihood of having a missing value in any of the name interpreters, and on the likelihood of giving the same answer to the third name interpreter. ${ }^{1}$ Apart from the modus of data collection, we use the following control variables

\footnotetext{
${ }^{1}$ For the likelihood of having a missing value in the inter-alter matrix and the likelihood of giving the same answers to all matrix items the marginal distributions and small numbers of cases prevent a meaningful multivariate analysis.
}

Table 2

Simple and multiple logistic regressions on three variables ${ }^{\mathrm{a}}$.

\begin{tabular}{lcc}
\hline & $\begin{array}{l}\text { Simple logistic } \\
\text { regression } \\
\text { coefficient } \\
\text { (standard error) }\end{array}$ & $\begin{array}{l}\text { Multiple logistic } \\
\text { regression } \\
\text { coefficient } \\
\text { (standard error) }\end{array}$ \\
\hline A: Dropout & $-1.91(0.78)^{*}$ & $-2.4(0.92)^{*}$ \\
Online vs. face-to-face & 0.130 & 0.417 \\
Nagelkerke $R^{2}(N=105)$ & $-1.61(0.68)^{*}$ & \\
B: Having a missing value in name interpreters & $-2.2(0.91)^{*}$ \\
Online vs. face-to-face & 0.122 & 0.446 \\
Nagelkerke $R^{2}(N=88)$ & $-1.89(0.68)^{* *}$ & \\
C: Same answer to third name interpreter for all alteri & $-1.93(0.82)^{*}$ \\
Online vs. face-to-face & 0.180 & 0.428 \\
Nagelkerke $R^{2}(N=75)$ & &
\end{tabular}

a Note: In all multivariate models the following control variables not shown in the table have been used: gender, appeal of cooperation with a commercial company, function, faculty (five dummies), extent of one's research being known in companies, additional job outside of the university. Significance values are based on Wald statistics.

$p<0.05$, significance values based on Wald statistics for logistic regressions ** $p<0.01$, significance values based on Wald statistics for logistic regressions.

that either represent demographic differences or are assumed to be correlated with an interest in participating in the survey: gender, appeal of cooperation with commercial company, function, faculty, to what extent one's own research is known in companies, and whether the respondent has another job outside of the university. Table 2 presents the effect of the modus of data collection in the single variable model and in the model with all independent variables. The control variables showed no consistent pattern of significance across the three dependent variables.

We see that in all three multivariate models the difference between the two groups of respondents remains significant. The effects of the contextual variables in our data do not explain the difference between the face-to-face group and the web survey group with respect to the probability to drop out, to have a missing value, or to give the same answers. We preliminarily conclude that there is cause for being concerned about the quality of ego-centered network data that were collected by means of an online questionnaire. However, the design of our pilot study does not allow us to derive clear conclusions because it is impossible to tell whether our results are the result of a lack of social control during the online data collection or a consequence of the self-selection of respondents. For example, it cannot be ruled out that less motivated respondents who in general have a higher likelihood of dropping out are more likely to be found in the group of respondents who have chosen the web questionnaire.

\section{An experimental comparison of online and offline data collection}

Given the findings of the first study we decided to test five hypotheses about the effects of the mode of data collection in a study with a randomized design. The underlying idea of the hypotheses is the assumption that the self-administration of a web survey, in combination with the time and effort needed for the network questions, make it tempting for the respondent to take shortcuts (Tourangeau et al., 2007). The hypotheses are formulated in such a way that their confirmation provides evidence for the idea that respondents in the web survey have a stronger tendency to save time by not filling out (some of the) questions or by filling them out mechanically.

H1. In the online group the dropout rate in the network part is higher than in the face-to-face group. 
H2. In the online group there is a higher proportion of respondents with a network size of zero than in the face-to-face group.

H3. For those who did not skip the name generators, in the online group the network size is smaller than in the face-to-face group.

H4. In the online group there is a higher proportion of respondents with missing values in the inter-alter response matrix than in the face-to-face group.

H5A. In the online group there is a higher density of the egocentered network of respondents than in the face-to-face group.

H5B. In the online group there is a higher proportion of respondents with a network density of one than in the face-to-face group.

In the summer of 2005 we asked a number of randomly selected researchers of three faculties at the University of Twente (NL) to participate in a short survey concerning their collaboration with (commercial) companies - the same topic as we used in the first study. In total, 282 researchers of the following 3 faculties participated: Science \& Technology (109), Electrical Engineering, Mathematics, and Computer Science (111), and Engineering Technology (61). One respondent did not give information about his/her faculty. From these $282,81.9 \%$ of the participants were male, $8.2 \%$ were full professors, $6.4 \%$ associate professors, $15.3 \%$ assistant professors, $11.0 \%$ researchers or postdocs, $57.7 \%$ were Ph.D. students, $1.4 \%$ had another function, and $0.4 \%$ (which constitute one respondent) did not give information about his or her function. The questionnaire was an extended and improved version of the one we used in the pilot study, and adjusted to answer the research questions of interest about university-company collaborations. At the end of the questionnaire the same four name generators used in the previous study were presented. However, we now gave the opportunity to mention up to four alteri per generator. Additionally, for those researchers who had an ongoing collaborative project with a commercial company we first asked the respondent "Please mention the name of your main collaboration partner". After that we prompted for up to two additional relevant persons that would be crucial in getting a new business cooperation going. So the maximum number of alteri in this study is $1+4 \times 4+2=19$. We then presented one name interpreter ("For every individual mentioned below, what is the strength of your relation with that person. A strong relationship would include frequent contact and regular exchange of information." Answer options were "strong", "weak", "non-existent", and "don't know".) and finally, the interalter response matrix. None of the questions were mandatory to answer. We made use of a randomized design allocating respondents either to a web survey or to a trained student interviewer. A respondent in the online condition received an email invitation and two email reminders with a link to the web survey. A respondent in the offline condition was called via telephone (up to three times) and asked for a face-to-face interview. The overall response rate is $282 / 909=31.0 \%$. The response rate in the online condition $(37.8 \%$, $\left.n_{1}=188\right)$ was higher than in the offline condition $(23.4 \%$ among those who could be contacted, $n_{2}=94$ ). Filling out the questionnaire took about 20-30 min. In all likelihood, the lower response rate compared to our first study is caused by the fact that in the pilot study it was clear from the invitation that the research was being conducted by researchers from the respondent's own university. Moreover, respondents who refused to be interviewed face-to-face, did not get the option to answer online (and vice versa).

Table 3 shows that in the group of respondents who filled out the web survey there is a significantly higher proportion of Ph.D. students $(62.6 \%$ vs. $47.9 \%, t=2.3, p=0.02)$ and a slightly, though not significantly smaller proportion of full professors $(6.4 \%$ vs. $11.7 \%$, $t=1.4, p=0.15$ ). We suspect that Ph.D. students are somewhat more likely than other staff to work at home resulting in difficulties
Table 3

Cross-tabulation of position by respondent group ${ }^{\mathrm{a}}$.

\begin{tabular}{lll}
\hline Position & Face-to-face interview & Web survey \\
\hline Full professor & $11(11.7 \%)$ & $12(6.4 \%)$ \\
Assoc. professor & $7(7.4 \%)$ & $11(5.9 \%)$ \\
Assist. professor & $20(21.3 \%)$ & $23(12.3 \%)$ \\
Postdoc & $9(9.6 \%)$ & $15(8.0 \%)$ \\
Researcher & $2(2.1 \%)$ & $5(2.7 \%)$ \\
Ph.D. student & $45(47.9 \%)$ & $117(62.6 \%)$ \\
Other & $0(0 \%)$ & $4(2.1 \%)$ \\
Missing values & 0 & 1 \\
Total (valid) & $94(100 \%)$ & $187(100 \%)$
\end{tabular}

a Calculated percentages in parentheses exclude respondent with missing value.

reaching them via telephone at their office. In line with this finding the group of web respondents is somewhat younger (33.2 vs. 35.7 years, $t=2.1, p=0.04$ for $\ln [\text { age] })^{2}$ and has had somewhat fewer collaborative projects during their career (3.8 vs. $4.6, t=2.9, p<0.01$ for $\ln [$ numbers]). The two groups of respondents do not differ with regard to the number of published articles (1.5 vs. $1.8, t=1.8, p=0.07$ for $\ln$ [numbers]), with regard to how appealing collaboration with a commercial company is $(t=0.04, p>0.5)$, and with regard to how important commercial applicability of their research is to them $(t=0.40, p>0.5)$. They also do not differ with regard to the success of their collaborations $(t=0.40, p>0.5)$. The differences in age and in the number of collaborative projects disappear after controlling for the respondent's position (two dummy variables: Ph.D. student and full professor, effect of online vs. offline: $t=-0.3, p>0.5$ for $\ln$ [age], $t=1.8, p=0.07$ for $\ln$ [number of collaborative projects]). The two groups of respondents do not differ significantly with respect to the number of missing values in any of the non-network variables (maximum number of missing values for some variables in the online group was 6 , in the face-to-face group it was 2). None of the respondents dropped out before the network part of the questionnaire.

The proportion of respondents who dropped out during the network part is significantly higher in the group who filled out the web survey $(18.8 \%$ vs. $4.4 \%$, Fisher's exact value $<0.01)$. Also, in the online group the proportion of respondents who did not fill out any name generator is significantly higher $(11.3 \%$ vs. $3.3 \%$, Fisher's exact value $=0.04$ ). Among those who did not skip the name generator questions, we find that the group of web respondents tend to fill in less names (5.6 vs. 8.2, $t=5.1, p<0.01$ for $\ln [$ numbers]). With respect to the fourth hypothesis we find that among the web respondents there are more missing values in the inter-alter response matrix (mean number of missing values 3.3 vs. 0.2 , Mann-Whitney Test $U=5537, p=0.02$ ). Also, the proportion of respondents who have any missing value in the matrix is higher among the web respondents $\left(25.5 \%\right.$ vs. $\left.14 \%, \chi^{2}=4.3, p=0.04\right)$. The density value (based on the binary items) is significantly higher in this group (mean density: 0.59 vs. $0.46, t=3.4, p<0.01$ ). Just like in study 1 , this can be understood by realizing that the proportion of respondents who claim that all their alteri are related is higher among the online respondents $\left(30.1 \%\right.$ vs. $\left.9.3 \%, \chi^{2}=13.3, p<0.01\right)$.

We then conducted a number of multiple linear and logistic regression analyses to find out whether any of the found differences in the network data between the two groups of respondents could be explained by other differences in the two samples. We included the following control variables: being a Ph.D. student, being a full professor, being male, faculty (two dummy variables), appeal of collaboration with commercial companies (5-point Likert scale), and experience with university-company collaboration ( $1=$ yes). In addition, for the multivariate tests of hypotheses $5 \mathrm{~A}$ and $5 \mathrm{~B}$ we

\footnotetext{
2 We use the natural logarithm for variables with some outliers.
} 
Table 4

Linear and logistic regressions.

\begin{tabular}{|c|c|c|c|c|c|c|}
\hline $\begin{array}{l}\text { Regression } \\
\text { Variables }\end{array}$ & $\begin{array}{l}1 \\
\text { Dropout }\end{array}$ & $\begin{array}{l}2 \\
\text { No name generator } \\
\text { filled in }\end{array}$ & $\begin{array}{l}3 \\
\text { Network size } \\
(\ln )\end{array}$ & $\begin{array}{l}4 \\
\text { Missing matrix } \\
\text { answer }\end{array}$ & $\begin{array}{l}5 A \\
\text { Density }\end{array}$ & $\begin{array}{l}\text { 5B } \\
\text { Same answers }\end{array}$ \\
\hline Face-to-face vs. online $($ online $=1$ ) & $1.45^{* *}(0.57)$ & $0.86(0.68)$ & $-0.328^{* *}(0.07)$ & $0.88^{*}(0.39)$ & $0.16^{*}(0.07)$ & $2.45^{*}(1.09)$ \\
\hline Full professor & $-0.35(0.85)$ & $-0.09(1.15)$ & $0.09(0.13)$ & $-0.19(0.71)$ & $-0.04(0.08)$ & $-1.13(1.15)$ \\
\hline Ph.D. student & $-0.48(0.43)$ & $-0.13(0.56)$ & $-0.19^{*}(0.07)$ & $0.32(0.38)$ & $0.04(0.05)$ & $0.19(0.45)$ \\
\hline Gender $($ male $=1)$ & $0.17(0.49)$ & $0.11(0.63)$ & $-0.13(0.87)$ & $-0.02(0.41)$ & $0.04(0.05)$ & $-0.19(0.47)$ \\
\hline Electr. Eng./Math/Comp. Science & $1.12(0.79)$ & $1.33(1.08)$ & $-0.10(0.09)$ & $0.08(0.44)$ & $-0.00(0.05)$ & $0.15(0.53)$ \\
\hline Science and Technology & $1.67^{*}(0.79)$ & $1.59(1.08)$ & $-0.23^{*}(0.09)$ & $-0.02(0.46)$ & $-0.08(0.05)$ & $-0.77(0.59)$ \\
\hline Appeal of collaboration & $0.21(0.23)$ & $0.20(0.29)$ & $-0.08^{*}(0.04)$ & $0.07(0.20)$ & $-0.02(0.02)$ & $-0.53^{*}(0.24)$ \\
\hline Ever had collaboration ( $1=$ yes $)$ & $-0.59(0.42)$ & $-0.80(0.56)$ & $0.19^{*}(0.07)$ & $-0.29(0.37)$ & $0.08(0.08)$ & $2.32^{*}(1.15)$ \\
\hline Network size & & & & $0.10^{*}(0.05)$ & $-0.02^{* *}(0.01)$ & $-0.41^{* *}(0.09)$ \\
\hline Interaction: Online $\times$ collaboration & & & & & $-0.12(0.08)$ & $-2.74^{*}(1.25)$ \\
\hline$n$ & 269 & 269 & 250 & $232^{\mathrm{a}}$ & 219 & 219 \\
\hline$R^{2} /$ Nagelkerke $R^{2}$ & 0.138 & 0.086 & 0.467 & 0.066 & 0.127 & 0.402 \\
\hline
\end{tabular}

Note: Interaction effects between any of the control variables and the online vs. offline condition not included in model 1-model 4 because of insignificance.

a Some web respondents filled in the matrix questions incorrectly and had to be removed.

* Significant at $<1 \%$. Standard errors in parentheses. Significance values based on Wald statistics for logistic regressions and on $t$-statistics for the linear regressions of model 3 and model 5A.

** Significant at $<5 \%$. Standard errors in parentheses. Significance values based on Wald statistics for logistic regressions and on $t$-statistics for the linear regressions of model 3 and model 5A.

control for the size of the network. Table 4 shows the results of the multiple linear and logistic regression analyses.

The difference in the dropout rates of the two groups of respondents (model 1 ) remains significant after controlling for other potential factors of influence, lending support to hypothesis 1. Apart from that, one can see that researchers within one faculty (Science and Technology) have a higher likelihood of dropping out during the network part. The likelihood of skipping all name generators (model 2) cannot be predicted very well by any of the variables. Most importantly, the difference between the two groups of respondents in the likelihood of skipping the name generators is no longer significant, refuting hypothesis 2 . Model 3 shows that the difference in the number of mentioned names among those who did not skip the name generator questions is still significant. The online respondents tend to fill out fewer names even when controlling for other factors, supporting hypothesis 3. In addition, researchers within the faculty of Science and Technology, Ph.D. students, and those to whom commercial collaboration is more appealing tend to fill out fewer names. The multivariate test of the fourth model shows that the difference in the likelihood to have any missing values in the inter-alter matrix between the two groups of respondents remains statistically significant $(p=0.02)$, supporting hypothesis 4 . In addition, those who filled out more names in the name generator questions are more likely to have missing values in the inter-alter matrix. The fifth model analyzes by means of a linear regression analysis the network density among those respondents who mentioned at least two alteri. It shows that when including the control variables the difference in the density values between the two groups of respondents is still significant. Respondents of the web survey report a significantly higher density in their network. Model 5B may shed some light on why that is the case. It reports the results of the logistic regression analysis of the likelihood to report that all alteri are linked with each other. There is a significant interaction effect between being in the group of web respondents and having collaborated with a commercial company before. Within the group of web respondents there is a significantly larger proportion of respondents with a network density of one. This difference, however, disappears within the subgroup of respondents who have had at least one collaboration with a commercial company. We regard the latter group as being more motivated to fill out the survey about commercial collaboration and consider this finding as partial support for hypothesis $5 \mathrm{~A}$ and $5 \mathrm{~B}$. Among the group of respondents who never had a commercial collaboration, being in the group of web survey respondents leads to a higher likelihood of choosing the same answer category for all questions on the alteri relationships. $^{3}$

We find strong support for three out of the five tested hypotheses and partial support for one of the remaining two (hypothesis 5 ). Among the group of web respondents we find a higher dropout rate during the network part of the survey. Among those respondents who did not skip the name generator questions we find that the web respondents tend to fill out fewer names, and they tend to have somewhat more missing values in the inter-alter matrix. In addition, for those respondents who never had a collaborative project with a commercial company and who are likely to be less motivated to fill out the questions we find that among the web respondents there is a larger proportion who always selects the first answer category in the drop-down menu of the items in the interalter response matrix. We regard these findings as supportive for the argument that respondents in a web survey have a stronger tendency to answer in a time-saving manner, which is likely to affect the quality of the network data. Alternative explanations, such as lack of familiarity with the use of drop-down menus, are unlikely given the technical sophistication of the respondents.

\section{Conclusion and discussion}

We tested the assumption that the collection of ego-centered network data with the help of web surveys leads to a reduction in the quality of the network data when compared to the traditionally used data collection by means of a face-to-face interview. Although researchers have started to use web surveys for the collection of ego-centered network data, there is a lack of empirical evidence clarifying to what extent, if at all, the quality of the data is affected by the change in the mode of data collection. The findings of a pilot study led us to believe that these tendencies might play a role and we subsequently tested five hypotheses about the impact of a lack of social control during web surveys in a randomized field study among university researchers. Our results support the notion that

\footnotetext{
3 It is surprising that those who have larger networks are less likely to select the same answer categories. This cannot be explained by the fact that they are more likely to leave out answers in the inter-alter response matrix. The negative effect of network size is significant when we restrict the analyses to those respondents who do not have any missing values (table available on request from authors). We cannot offer an explanation of this negative effect.
} 
among the group of web respondents there is a larger tendency to answer the ego-network questions in a time-saving manner that will reduce the quality of the collected data.

Our analyses have some limitations. Since we conducted field studies, the two groups of respondents were not completely homogenous despite their random allocation to the modus of data collection. However, there is no indication that the differences affect the results and conclusions. Another limitation concerns the studied population, university researchers, which may be different from other target populations. We suspect that the chosen population of university researchers tends to be more motivated to fill out a lengthy and time-consuming questionnaire than many other respondents. We therefore suspect that the lack of social control during web surveys in other populations might affect the quality of the social network data even more. In addition, we tried only one specific kind of implementation of the ego-network questions. It might be that different ways to ask the ego-network questions (for instance using radio buttons instead of drop-downs in the interalter response matrix, or more visually appealing ways of posing the questions) will alleviate the problem to some extent. In addition, in both studies we placed the network questions at the end of the questionnaire. Nevertheless we assume that this placement did not decrease the respondent's motivation because it is known that most dropout in web surveys takes place in earlier phases of the filling in procedure (Conrad et al., 2005; Matzat et al., 2009). However, in shorter surveys the differences between web survey data and data collected face-to-face may be smaller. Generalization of our findings to the online measurement of other types of social networks is debatable. It is an open question for further research whether answering questions about for instance more emotionally involving relationships leads to more accurate self-reported information. Finally, we cannot compare the networks we measured with the "real" network for the lack of a clear-cut outside validity criterion.
However, we do feel that our results suggest that the validity of the offline results is better, especially given the number of respondents simply selecting the first answer from the drop-down list in the inter-alter response matrix.

The results of the study have some important implications. Most of all, they are a warning for researchers who consider collecting ego-centered network data by means of a web survey. Simply copying the standard design of the questions that is being used in face-to-face interviews can have a negative impact on the quality of the results. Rather, researchers should put additional efforts in motivating the respondents to spend time on filling out the network questions properly. Unfortunately, at the moment there is only very limited knowledge available clarifying which elements of a web survey could increase the respondent's motivation to fill out the time-consuming network questions carefully. Second, our findings underline the importance of research that analyzes effects of variations in the design of web surveys. The existing studies, e.g., Lozar Manfreda et al. (2004) and Coromina and Coenders (2006), are a first step. However, much more attention should be devoted to design elements that have the potential to motivate the respondent. Interactive elements including optional short videos or other more graphical ways of probing the network questions may be helpful. Third, the results indicate that methodological studies examining mode effects of a web survey should not take the answers in the network part of the questionnaire for granted. High correlations between answers might be an artefact produced by undesirable time-saving answering tendencies during web surveys. Examining these tendencies in method studies of web surveys should have a high priority for social network researchers.

Appendix A. First two name generators: within own faculty contacts and outside own faculty contacts*

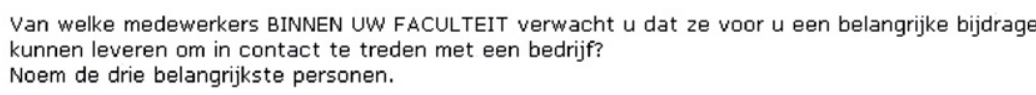

Van welke medewerkers BINNEN UW FACULTEIT verwacht $u$ dat ze voor $u$ een belangrijke bijdrage kunnen leveren om in contact te treden met een bedrijf? Noem de drie belangrijkste personen.

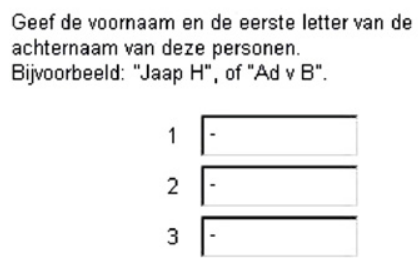

Van welke medewerkers BUITEN UW FACULTEIT MAAR BINNEN DE UNIVERSITEIT verwacht $u$ dat ze voor $u$ een belangrijke bijdrage kunnen leveren om in contact te treden met een bedrijf? Noem de drie belangrijkste personen.

Geef de voornaam en de eerste letter van de achternaam van deze personen. Bijvoorbeeld: "Jaap H", of "Ad v B

1

2

3
-
$+2$

$+$
Indien u de betreffende persoon al eerder hebt genoemd, geef dit dan hieronder aan

heb ik al eerder genoem

heb ik al eerder genoemd

heb ik al eerder genoemd

Denk goed na over uw antwoorden: u kunt uw antwoorden op deze pagina niet meer herzien.

*: English translations:

Question 1: "From which colleagues WITHIN YOUR OWN FACULTY do you expect that they might be able to help you substantially to get in contact with a commercial company? Please mention the three most important persons." Question 2: "From which colleagues OUTSIDE OF YOUR OWN FACULTY BUT WITHIN YOUR UNIVERSITY do you expect that they might be able to help you substantially to get in contact with a commercial company? Please mention the three most important persons. If you mentioned the person already in the earlier question, then indicate this below." 


\section{Appendix $\mathrm{B}^{+}$. The inter-alter response matrix*}

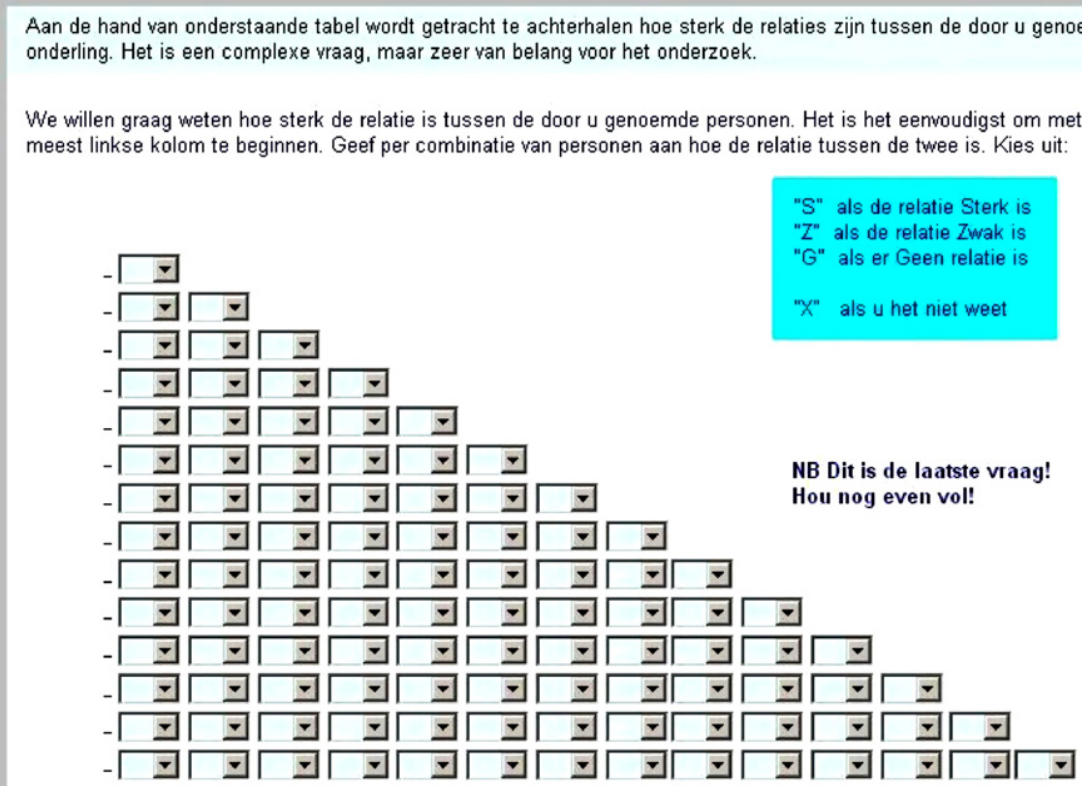

*Note: For every mentioned alter, the respondent would see the corresponding name in every row and column of the matrix.

+ : English translation:

"With the help of this table we intend to find out how strong the relations are between the persons you mentioned earlier. This is a complex issue, but it is important for this research.

We would like to know how strong the relations are between all the persons you mentioned. The easiest way to answer the question is to start with the left column. For every pair of individuals, please indicate how strong their relation is. You can choose between "S" (strong relation), "Z" (weak relation), "G" (no relation), and "X" (don't know)."

\section{References}

Adams, J., Moody, J., 2007. To tell the truth: measuring concordance in multiply reported network data. Social Networks 29, 44-58.

Bell, D.C., Belli-McQueen, B., Haider, A., 2007. Partner naming and forgetting: recall of network members. Social Networks 29, 279-299.

Bernard, H.R., Killworth, P.D., Sailer, L., 1982. Informant accuracy in social network data. V. An experimental attempt to predict actual communication from recall data. Social Science Research 11, 30-66.

Brewer, D.D., 2000. Forgetting in the recall-based elicitation of personal and social networks. Social Networks 22, 29-43.

Burt, R.S., 1984. Network items and the General Social Survey. Social Networks 6 , 293-339.

Burt, R.S., 1997. A note on social capital and network content. Social Networks 19, 355-373.

Conrad, F., Couper, M., Tourangeau, R., Peytchev, A., 2005. Impact of progress feedback on taks completion: first impressions matter. In: Paper Presented at the Conference CHI 2005, Portland, Oregon, USA, April 2-7.

Coromina, L., Coenders, G., 2006. Reliability and validity of egocentered network data collected via web. A meta-analysis of multilevel multitrait multimethod studies. Social Networks 28, 209-231.

Crawford, S.D., Couper, M., Lamias, M.J., 2001. Web surveys: perception of burden. Social Science Computer Review 19, 146-162.

Freeman, L.C., Romney, A.K., Freeman, S.C., 1987. Cognitive structure and informant accuracy. American Anthropologist 89, 310-325.

Killworth, P.D., Bernard, H.R., 1976. Informant accuracy in social network data. Human Organization 35, 269-286.

Kogovsek, T., Ferligoj, A., Coenders, G., Saris, W.E., 2002. Estimating the reliability and validity of personal support measures: full information ML estimation with planned incomplete data. Social Networks 24, 1-20.
Kogovsek, T., Ferligoj, A., 2004. The quality of measurement of personal support subnetworks. Quality and Quantity 38, 517-532.

Kogovsek, T., 2006. Reliability and validity of measuring social support networks by web and telephone. Metodolzski zvezki 3, 239252.

Lozar Manfreda, K., Vehovar, V., Hlebec, V., 2004. Collecting ego-centred network data via the web. Metodolzski zvezki 1, 295-321.

Marin, A., 2004. Are respondents more likely to list alters with certain characteristics? Implications for name generator data. Social Networks 26, 289-307.

Marsden, P.V., 1990. Network data and measurement. Annual Review of Sociology $16,435-463$.

Marsden, P.V., 2003. Interviewer effects in measuring network size using a single name generator. Social Networks 25, 1-16.

Matzat, U., Snijders, C., van der Horst, W., 2009. The effects of different types of progress indicators on drop-out rates in web surveys. Social Psychology 40, 43-52.

McCarty, C., Killworth, P.D., Rennell, J., 2007. Impact of methods for reducing respondent burden on personal network structural measures. Social Networks 29, 300-315.

McPherson, M., Smith-Lovin, L., Brashears, M.E., 2006. Social isolation in America: changes in core discussion networks over two decades. American Sociological Review 71, 353-375.

Tourangeau, R., Rips, L.J., Rasinski, K., 2007. The Psychology of Survey Response, 7th ed. Cambridge University Press, Cambridge.

Vehovar, V., Lozar Manfreda, K., Koren, G., Hlebec, V., 2008. Measuring ego-centered social networks on the web: questionnaire design issues. Social Networks 30, 213-222. 